\title{
Stroke prevention in atrial fibrillation: Commentary regarding the AAN's evidence-based guideline update
}

Antonio Culebras, MD, FAAN, FAHA, Steven R. Messé, MD, FAAN, FAHA: We thank Drs. Hart and Eikelboom ${ }^{1}$ for their insightful commentary in Neurology ${ }^{\circledR}$ Clinical Practice regarding the American Academy of Neurology (AAN) evidence-based guideline update on atrial fibrillation $(\mathrm{AF}){ }^{2}$ Both authors have extensively researched stroke prevention in patients with $\mathrm{AF}^{3}$ and we respect their views. The Commentary states, "atrial fibrillation patients with prior ischemic stroke or TIA benefit the most from anticoagulation and should receive anticoagulation, if it can be given safely." We could not agree more. The AAN guideline development process yields a Level B recommendation when clinicians "should" provide a therapy; a Level A recommendation is limited to situations when clinicians "must" provide a therapy. As the Commentary authors have implied, there are circumstances when anticoagulation cannot be safely given, and the guideline panel determined that clinical judgment was paramount in the final decision. Thus, a Level B was applied, which remains a strong recommendation.

Cognizant of the AAN's global reach, we included a recommendation to consider the administration of triflusal (a generic product available in developing countries) with lowintensity acenocoumarol in patients with $\mathrm{AF}$ at intermediate stroke risk and higher bleeding risk (Level B). ${ }^{4}$ In many developing countries, new oral anticoagulants may not be available or affordable, and this evidence-based recommendation fills the gap.

SUNY Upstate Medical University (AC), Syracuse, NY; and the University of Pennsylvania and the Pennsylvania Hospital (SRM), Philadelphia.

This letter is copublished in Neurology ${ }^{\circledR}$ and Neurology: Clinical Practice.

Disclosures: A. Culebras has received funding for travel from J. Uriach \& Co. S.A.; serves as an Associate Editor for Medlink; receives publishing royalties for Case Studies in Sleep Neurology (Cambridge University Press UK, 2012) and Sleep Apnea, Stroke and Cardiovascular Disease (Cambridge University Press UK, 2013); and holds stock in Clinical Stroke Research, Inc., NY. S.R. Messé serves on a DSMB for the NIH/National Institute of Neurological Disorders and Stroke; receives publishing royalties from UpToDate, Inc.; serves as a consultant for GlaxoSmithKline; and receives research support from WL Gore, GlaxoSmithKline, and the NIH (NIDDK, National Institute of Neurological Disorders and Stroke, NHLBI).

1. Hart RG, Eikelboom JW. Stroke prevention in atrial fibrillation: commentary regarding the AAN's evidence-based guideline update. Neurol Clin Pract 2014;4:96-98.

2. Culebras A, Messé SR, Chaturvedi S, Kase CS, Gronseth G. Summary of evidence-based guideline update: prevention of stroke in nonvalvular atrial fibrillation: report of the Guideline Development Subcommittee of the American Academy of Neurology. Neurology 2014;82:716-724.

3. American Academy of Neurology. Practice parameter: stroke prevention in patients with nonvalvular atrial fibrillation: report of the Quality Standards Subcommittee of the American Academy of Neurology. Neurology 1998;51:671-673.

4. Pérez-Gómez F, Alegría E, Berjón J, Iriarte JA, Zumalde J, Salvador A; for the NASPEAF Investigators. Comparative effects of antiplatelet, anticoagulant, or combined therapy in patients with valvular and nonvalvular atrial fibrillation: a randomized multicenter study. J Am Coll Cardiol 2004;44:1557-1566.

\section{Health literacy and medication awareness in outpatient neurology}

William M. Landau, MD: The article by Fleisher et al. ${ }^{1}$ about patient health literacy and medication awareness is the scientific premise that for me confirms three score years of 
academic center pedagogy. Operational free associations: (1) Beyond electronic records, ours is a personally rewarding chronic disease specialty. (2) Scheduled visits are the most effective, least expensive antifrustration tactic, especially for the same resident who writes brief progress notes and even takes essential phone calls. (3) Medicalese vocabulary is never to be relied upon. (4) The most important compliance gimmick is the 7-hole flip-top plastic pill box, one for each daily pill time, plus at least one benign family mentor who checks pill box compliance and prescription renewal. (5) Alleged medication compliance via the primary stock bottle is inevitably sloppy. (6) This article ought to be exposed early on to all instructors, residents, and students.

Washington University, St. Louis, MO.

Disclosures: The author reports no disclosures.

Authors Respond: Jori Fleisher, MD, Roma Bhatia, BA, Colton Margus, BA, Amy Pruitt, MD, Nabila Dahodwala, MD, MS: We thank Dr. Landau for his comments. We agree that the practice of neurology continues to be a thriving and intellectually stimulating specialty with immense opportunities for satisfying, long-term relationships with patients. While electronic medical records can present time-consuming barriers to patient care, we can also begin to use them to our patients' advantage from a health literacy perspective. Many systems allow for free-text entry of patient instructions that can contain individualized, plain-language information about the patient's condition, or even simple pictographic medication schedules. In addition to supportive family members and the invaluable pill box with daily compartments, smartphones now provide a nearly ubiquitous and underappreciated resource for setting multiple daily, labeled alarms as medication reminders.

As neurology advances and clinical trials reveal new treatments with robust success rates, we will still falter in practice if we do not elicit and address the concerns of our patients that limit understanding. No matter how vast the improvements in science and technology, we maintain that clear, plain language, nonjudgmental communication between health care providers and their patients remains the most powerful agent of change in medicine today.

University of Pennsylvania School of Medicine (JF, CM, AP, ND), Philadelphia; and the Mayo Clinic (RB), Rochester, MN.

Disclosures: J.E. Fleisher receives an unrestricted educational grant from Medtronic and is supported by NIH T32-NS061779. R. Bhatia reports no disclosures. C. Margus received compensated support of the Bill \& Melinda Gates Foundation's Beijing Representative Office. A. Pruitt has received speaker honoraria from the American Academy of Neurology and serves as a Section Editor for Current Treatment Options in Neurology. N. Dahodwala has received funding for travel from the Movement Disorders Society and the National Parkinson Foundation; receives an investigator-initiated grant from Teva Pharmaceuticals; and receives research support from the NIH (NIA and National Institute of Neurological Disorders and Stroke), Parkinson Council, and National Parkinson Foundation.

1. Fleisher J, Bhatia R, Margus C, Pruitt A, Dahodwala N. Health literacy and medication awareness in outpatient neurology. Neurol Clin Pract 2014;4:71-81.

\section{Osteoporosis for the practicing neurologist}

Khichar Shubhakaran, MBBS, MD, Rekha Jakhar Khichar: We read the article on osteoporosis by Rothman et al. ${ }^{1}$ with interest and found it worth additional discussion for its practical implications. A neurologist may face osteoporosis as myelopathy, radiculopathy, osteomalacic myopathy, hypokalcemic tetany, seizure, aches, pains, encephalopathy, and irritability. In India there are no epidemiologic data on exact prevalence. The men:women ratio may be distorted because men are more likely to be brought for hospital care. ${ }^{2}$ Nonmodifiable risk factors include female sex, old age, small and thin build, Caucasian/Asian ethnicity, and 
family history of fractures. Important modifiable risk factors include calcium and vitamin D deficiency, sedentary lifestyle, smoking, and excessive alcohol and caffeine intake. ${ }^{2}$ Medical conditions like hypogonadism, thyrotoxicosis, Cushing syndrome, anorexia nervosa, malabsorption syndromes, chronic liver and renal disease, drugs like glucocorticoids and anticonvulsants, and chronic inflammatory conditions like rheumatoid arthritis may lead to secondary osteoporosis. Therefore, physicians and respective specialists may play a great role in preventing this silent killer. ${ }^{2}$

In general, Indians have poor bone health, and osteoporosis is common in India. Peak bone mass achieved during puberty is a strong predictor of development of osteoporosis in later years. High prevalence of vitamin D deficiency in India is a major contributor to low bone mass. As a public health measure, it is important to encourage children to drink milk and play in the sun. This will ensure adequate calcium intake, vitamin D synthesis, and exercise. These 3 are the crucial elements in determining peak bone mass. There is thus an urgent need for greater public awareness in this regard. For the middle-aged and elderly, early detection and treatment of osteoporosis with available agents can reduce the risk of fractures and associated morbidity and mortality.

Balanced diet is a must to have healthy bones and avoid complications related to osteoporosis. Adequate nutrition is important throughout pregnancy. Thus the nutritional needs of both mother and child must be considered. Breastfeeding should be encouraged to give children a good skeletal start. Birthweight is linked to adult bone mineral content and there is evidence that low birthweight relates to higher rates of osteoporotic fracture in adult life. Inadequate nutrition in early childhood may have persisting adverse effects on bone. Adults who consumed milk less than once a week in childhood and adolescence have higher rates of osteoporotic fractures later in life.

Dr. S.N. Medical College, Jodhpur, Rajasthan, India.

Disclosures: The authors report no disclosures.

Authors Respond: Micol S. Rothman, MD, Sterling G. West, MD, Michael T. McDermott, MD: We thank Drs. Shubhakaran and Khichar for their comments and appreciate the added discussion of practical implications from the Indian population perspective. We agree that specialists in all countries can play a vital role in identifying and treating patients with osteoporosis.

University of Colorado School of Medicine, Denver.

Disclosures: M.S. Rothman reports no disclosures. S.G. West serves on a scientific advisory board for Amgen and owns stock in Novartis. M.T. McDermott reports no disclosures.

1. Rothman MS, West SG, McDermott MT. Osteoporosis for the practicing neurologist. Neurol Clin Pract 2014;4:34-43.

2. Malhotra N, Mithal A. Osteoporosis in Indians. Indian J Med Res 2008;127:263-268.

\section{Sleep medicine practice adaptations}

Nitin K. Sethi, MD: I read with interest Raphaelson and Brown's article on sleep medicine practice adaptations. ${ }^{1}$ As a neurologist with subspecialty certification in sleep medicine, I see patients in my hospital's sleep center 2 half-days a week. Recent payment policy changes by Medicare and commercial medical insurance companies have made it increasingly difficult to get an in-laboratory (attended) sleep study approved for the sleep apnea patient who has no other cardiovascular comorbidities. Even if I strongly suspect moderate to severe grade of sleep-disordered breathing in that patient, I have stopped requesting peer-to-peer review since I know that my peer on the other end of the line has 
his or her hands bound. The answer is going to be "no and request denied" even though he or she may acknowledge (off the record) that I have a valid case. So it is not uncommon for me to order a home sleep study only to find it substandard. Then I am forced to either treat my patient on the basis of that or to request an in-laboratory study and hope to get it approved this time around. Fraudulent practices in the past by some should not result in radical policy changes that apply to all physicians and are detrimental to our patients. The pendulum has swung from in-laboratory sleep study for any and every indication to in-laboratory study only for the patient with documented cardiovascular comorbidities. I hope somewhere between these 2 extremes there is a middle ground where common sense prevails.

New York-Presbyterian Hospital, New York.

Disclosures: N. Sethi serves as Associate Editor for The Eastern Journal of Medicine.

Author Responds: Marc Raphaelson, MD, FAAN, FAASM: It is getting harder to defend our patients' best interests, but we cannot just surrender. We need the patient actively involved to fully realize the benefits of insurance contracts they have accepted. We need to remind our medical societies to advocate vigorously for easier access to needed care. If our readers can share their successful advocacy methods, we would like to hear them. Clinical science and public policy continue to evolve. We hope that our article might help both practitioners and our colleagues who work as carrier medical directors better to triangulate the "middle ground" of best practices.

Leesburg, VA.

Disclosures: M. Raphaelson serves on the Scientific Advisory Board and speakers' bureau and has received funding for travel and speaker honoraria from Jazz Pharmaceutical; practices sleep medicine and bills for related services; is president of Marc Raphaelson, MD, PA, Inc., which collects fees from governmental and commercial insurers; serves as Medical Director for SleepMed, Inc., a for-profit entity providing sleep medicine testing and treatment; and has prepared affidavits for Sleep Information Systems, a now-dissolved for-profit entity.

1. Raphaelson M, Brown DB. Sleep medicine practice adaptations. Neurol Clin Pract 2014;4:63-70.

\section{Unrecognized cobalamin deficiency, nitrous oxide, and reversible subacute combined degeneration}

Praburam Selvaraj, MBBS, MD, FRCA, FFPMRCA, Vijayendra Chikkabbaiah, MBBS, FRCA: We read with interest the case report of unrecognized cobalamin deficiency, nitrous oxide, and reversible subacute combined degeneration by Jordan et al. ${ }^{1}$ We congratulate the authors for recognition, clinical diagnosis, and appropriate management of the patient. We note that this article mentions nitrous oxide as NO (nitric oxide) rather than $\mathrm{N}_{2} \mathrm{O}$. Nitric oxide $(\mathrm{NO})$ and nitrous oxide $\left(\mathrm{N}_{2} \mathrm{O}\right)$ are used for different clinical needs and have differing mechanisms of action, metabolism, and adverse effects. ${ }^{2,3}$ Although throughout the article the effects of nitrous oxide are rightly mentioned, the use of chemical formula $\mathrm{NO}$ might be confusing to readers.

The Royal Derby Hospital, UK.

Disclosures: The author reports no disclosures.

Authors Respond: Justin T. Jordan, MD, Julia Weiser, BA, Paul C. Van Ness, MD: We thank Drs. Selvaraj and Chikkabbaiah for their comments, and appreciate their feedback on our 
report. The abbreviation NO was employed as initials for nitrous oxide rather than a chemical formula, though we concur that this nonstandard abbreviation may introduce uncertainty to readers. As such, the definitive publication of our report will abbreviate nitrous oxide as $\mathrm{N}_{2} \mathrm{O}$.

Massachusetts General Hospital (JTJ), Boston; and University of Texas Southwestern Medical Center (JW, PCVN), Dallas.

Disclosures: J.T. Jordan and J. Weiser report no disclosures. P.C. Van Ness serves on the Editorial Board of Archives of Neurology and receives research support from UCB, NeuroPace, and Eisai.

1. Jordan JT, Weiser J, Van Ness PC. Unrecognized cobalamin deficiency, nitrous oxide, and reversible sub-acute combined degeneration. Neurol Clin Pract Epub 2014 Mar.

2. Chanarin I. The effects of nitrous oxide on cobalamins, folates, and on related events. Crit Rev Toxicol 1982;10:179-213.

3. Wennmalm A, Benthin G, Edlund A, et al. Metabolism and excretion of nitric oxide in humans: an experimental and clinical study. Circ Res 1993;73:1121-1127.

\section{What Do You Think?}

Discover what your colleagues in clinical practice are talking about. And then add to the discussion!

Neurology ${ }^{\circledR}$ Clinical Practice welcomes your feedback on our articles and seeks your practical, real-world experience on how you face opportunities and challenges in clinical practice. Correspondence regarding articles that appear in Neurology: Clinical Practice may be sent via e-mail to NCPjournal@neurology.org or by clicking on the "Respond" button in the right column of a full text version of an article. 


\title{
Neurology ${ }^{\circ}$ Clinical Practice
}

\author{
Health literacy and medication awareness in outpatient neurology \\ William M. Landau, Jori Fleisher, Roma Bhatia, et al. \\ Neurol Clin Pract 2014;4;182-183 \\ DOI 10.1212/01.CPJ.0000451406.84778.f9
}

This information is current as of June 9, 2014

$\begin{array}{ll}\begin{array}{l}\text { Updated Information \& } \\ \text { Services }\end{array} & \begin{array}{l}\text { including high resolution figures, can be found at: } \\ \text { http://cp.neurology.org/content/4/3/182.2.full.html }\end{array} \\ \text { References } & \begin{array}{l}\text { This article cites } 1 \text { articles, } 1 \text { of which you can access for free at: } \\ \text { http://cp.neurology.org/content/4/3/182.2.full.html\#\#ref-list-1 }\end{array} \\ \text { Permissions \& Licensing } & \begin{array}{l}\text { Information about reproducing this article in parts (figures,tables) or in } \\ \text { its entirety can be found online at: } \\ \text { http://cp.neurology.org/misc/about.xhtml\#permissions }\end{array} \\ & \begin{array}{l}\text { Information about ordering reprints can be found online: } \\ \text { http://cp.neurology.org/misc/addir.xhtml\#reprintsus }\end{array}\end{array}$

Neurol Clin Pract is an official journal of the American Academy of Neurology. Published continuously since 2011, it is now a bimonthly with 6 issues per year. Copyright (C) 2014 American Academy of Neurology. All rights reserved. Print ISSN: 2163-0402. Online ISSN: 2163-0933.

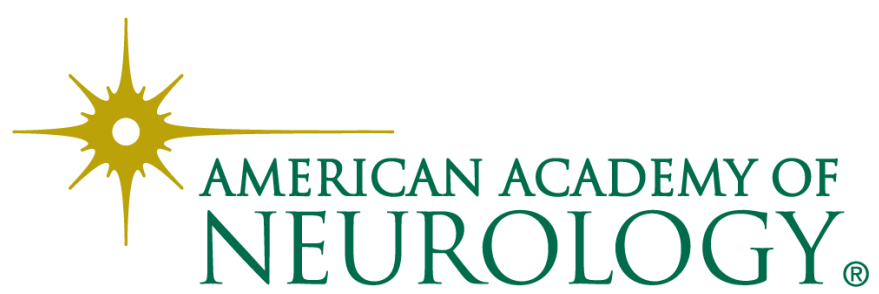

